\title{
Assessment of Renal Pathology among Saudi Population at Tabuk City-KSA Using Computed Tomography
}

Alaa Ibrahim Ahmed*, Nisreen Hassan, Naglaa Elsir, Amna Moahamed, Nmariq Mohamed, Dalal Albalawi, Nouf Almateri, Maryam Albalawi, Fatimah alshhri

Department of Radiological Sciences, Al Ghad International Colleges-Tabuk, 15, Al Faisaliyah Ashamaliyah, Tabuk 47315, Saudi Arabia

DOI: $10.36347 /$ sjams.2020.v08i11.003

| Received: 31.08 .2020 | Accepted: 08.09.2020 | Published: 03.11.2020

*Corresponding author: Alaa Ibrahim Ahmed

Abstract

This was retrospective cross sectional study to assess renal pathology using computed tomography CT was done in King Fahd Specialist hospital _ Tabuk -Saudi Arabia from first February 2020 to May 2020. The problem of study was increase kidney diseases that leads to kidney failure and importance to reduce the risk factors that lead to kidney disease. The objectives of the study were to show the role of CT scan in assessment renal pathology among Saudi population. The data were collected variables using CT scanner unit (Siemens's) with helical generation, through 30 patients with different clinical disorders for renal pathology. The results revealed that the CT tomography has an effective role in assessment renal pathology with confirmed laboratory investigation with significant confidence at $\mathrm{P}$ value (0.00). Researchers recommended that CT scan is better for renal pathology.

Keywords: Computed Tomography, renal pathology, laboratory investigations.

Copyright ( 12020 The Author(s): This is an open-access article distributed under the terms of the Creative Commons Attribution 4.0 International License (CC BY-NC 4.0) which permits unrestricted use, distribution, and reproduction in any medium for non-commercial use provided the original author and source are credited.

\section{BACKGROUND}

Computed tomography (CT) is a diagnostic imaging test used to create detailed images of internal organs, bones, soft tissue and blood vessels. The crosssectional images generated during a CT scan can be reformatted in multiple planes, and can even generate three-dimensional images which can be viewed on a computer monitor, printed on film or transferred to electronic media. CT scanning is often the best method for detecting many different diseases since the images allow to confirm the presence of a pathology and determine its size and location. CT is fast, painless, noninvasive and accurate. In emergency cases, it can reveal internal injuries and bleeding quickly enough to help save lives.

CT scans may be done with or without "contrast." Contrast refers to a substance taken by mouth or injected into an intravenous (IV) line that causes the particular organ or tissue under study to be seen more clearly computed tomography is concern about certain types of kidney or bladder problem. Renal computed tomography tests can show size of the kidney, signs of injury to the kidneys, abnormalities present since birth the presence of blockages or kidney stones, complications of a urinary tract infection (UTI) and cysts or tumors [1].
Many studies shows the relationship of Renal Length with Height and Weight of an individual using Computed Tomography. Variety of clinical disorders such as diabetes mellitus, chronic hypertension, renal artery stenosis, chronic renal failure affects the kidney and alters renal length. It also varies according to height, weight, age and ethnicity. So there should be standardized values for renal length to evaluate the pathological condition of kidney. In study aimed to determine the normal range of renal length and also to evaluate the relationship of renal length with body height and body weight of an individuals used abdominal Computed Tomography (CT) scans of 70 individuals between the age of 21-79 years without any renal disease were reviewed and their anthropometric data like height, weight, age and sex were also recorded. Renal length was calculated as the maximum longitudinal length in coronal section parallel to the renal long axis by using CT scan images of abdomen. The study results were the mean renal length of the total study population group was $9.38 \pm 1.08 \mathrm{~cm}$ and $9.23 \pm 0.92 \mathrm{~cm}$ for left and right kidney respectively. Mean height for the study group was $158.53 \pm 9.64 \mathrm{~cm}$ and mean weight was $49.24 \pm 9.77 \mathrm{~kg}$. Researchers found significant relationship between renal length and height of an individual in combined group consisting of both males and females whereas, weight of an individual did not show any significant relationship 
with renal length when correlation was done in combined group. Moreover, renal length was in negative relationship with age which was statistically significant for total population group (Left kidney $\mathrm{p}=0.0001$, Right kidney $\mathrm{p}=0.011$ ) [1].

In another study of Nephrolithiasis Based on Extracted Features of CT-Scan Images Artificial Neural Networks. Nephrolithiasis or Renal calculi are a general cause of bloody urine and flank pain in the abdomen. To locate the position, size and number of stones in the renal structure the patient is recommended to take computed tomography (CT-scan). As there is rapid raise in population the necessitate of more nephrologists is essential. So, the most important objective of this paper is to afford a supportive diagnosis system to the physician using general networks in order to envisage nephrolithiasis based on extracted features of CT-scan. The proposed system incriminates with pre-processing, segmentation, feature extraction by applying neural network techniques and finally prediction of kidney stone is done. Artificial Neural networks are intermittently used as a dominant distinctive classifier for errands in medical diagnosis for premature detection of diseases. and introduced a Feed- Forward Back propagation algorithm to lessen the diagnosis time and raise the accuracy of the system. The algorithm is introduced to extort the features which are used to train the network. The proposed system uses 22 input nodes, 10 hidden nodes and 1 output node. The network is trained until it targets its desired output. This trained network is used to cart out the classification automatically for a new model. The proposed system is tested with 50 real time samples, amid them $60 \%$ are used for training the network and $40 \%$ are used for testing the network. The intended system is implemented using MATLAB 8.5 software tool [2].

Other study in Relationship between Renal Volume Calculated by Using Multi-slice Computed Tomography and Glomerular Filtration Rate Calculated by Using the Cockcroft-Gault and Modification of Diet in Renal Disease Equations in Living Kidney Donors. The study aimed to estimate the donor's glomerular filtration rate (GFR). For this purpose, the modification of diet in renal disease (MDRD) and the CockcroftGault (CG) formulas has been used. However, these two formulas produce different results and finding new techniques with greater accuracy is required. Measuring the renal volume from computed tomography (CT) scan may be a valuable index to assess the renal function. This study was conducted to investigate the correlation between renal volume and the GFR values in potential living kidney donors referred to the multislice imaging center at Alzahra Hospital during 2014. The study comprised 66 subjects whose GFR was calculated using the two aforementioned formulas. Their kidney volumes were measured by using 64-slice CT angiography and the correlation between renal volume and GFR values were analyzed using the Statistical Package for the
Social Science software. There was no correlation between the volume of the left and right kidneys and the MDRD-based estimates of GFR ( $P=0.772, r=0.036, P$ $=0.251, \mathrm{r}=0.143$, respectively). A direct linear correlation was found between the volume of the left and right kidneys and the CG-based GFR values ( $\mathrm{P}=$ $0.001, \mathrm{r}=0.397, \mathrm{P})[3]$.

Study of Kidney cancer in Saudi Arabia aimed to evaluate available epidemiological data and risk factors for kidney cancer in a tertiary care center in Riyadh, Saudi Arabia, over a period of 25 years. The study was retrospective study conducted in a tertiary care center included all adult patients with primary kidney cancer who presented and were managed between 1990 and 2015. Based on this information, they forecast the incidence of the disease in their center over the next 5 years (2016 to 2020). Their results were in total, 371 patients were included in the study. The mean age of the patients was 56.3 years and the majority were male $(61 \%)$. Among the patients, $55.8 \%$ were diagnosed incidentally. At the time of diagnosis, $53.2 \%$ were hypertensive, $46.2 \%$ were diabetic, $39.1 \%$ had dyslipidemia, and $25 \%$ were smokers. In addition, most patients were obese $(42.3 \%)$ or overweight $(30 \%)$ [4].

Prevalence and characterization of urolithiasis in the Western region of Saudi Arabia. The main objective of this study was to determine the prevalence and risk factors of urolithiasis among the Saudi population in Makkah region. The study was a cross-sectional survey was conducted on February 2017 in Makkah region (Makkah, Jeddah, and Taif). Data were obtained through direct interviews with participants, using an 18-questions-self-questionnaire, inquiring about demographic data (age, gender, weight, height, location, and occupation), educational level, history of renal stone disease (symptoms, modality of diagnosis, hospital admission, and previous treatment), and risk factors of stone formation such as family history and daily fluid intake. The results were a total of 1506 individuals were interviewed. The overall percentage of those diagnosed urolithiasis was $6.2 \%$; including $6.6 \%$ males and $5.8 \%$ females $(\mathrm{P}=0.06)$. Of those with stones, $5 \%$ were medically treated, $1.7 \%$ were hospitalized, and $1.2 \%$ were surgically managed for stones. There was a positive linear correlation between the prevalence of stones and participants' age group $(\mathrm{r}=0.87, \mathrm{P}=0.01)$. Urolithiasis was reported by $8.9 \%$ obese participants, $5.9 \%$ overweight, and $5.4 \%$ with normal body mass index $(\mathrm{r}=0.68, \mathrm{P}=0.03)$. When stratified by jobs, stone prevalence significantly increased in retired participants $(17.2 \%)$ than in workers $(8.8 \%)$, followed by those without work $(7.7 \%)$ and finally by students $(3.3 \%) \quad(\mathrm{P}<0.001)$. There was no significant difference between urolithiasis and type of drinking water $(\mathrm{P}=0.62)[5]$. 


\section{Examination Technique and Protocol}

Computed tomography (CT) of the abdomen and pelvis is a diagnostic imaging test used to help detect diseases of the renal diseases and is often used to determine the cause of unexplained pain. Before starting exam the female patients must tell doctor if there's a possibility of pregnant and discuss any recent illnesses, medical conditions, medications that the patient is taking, and allergies. The Scout view is taken for abdomen and pelvis followed by cuts with or without contrast media cover all the region of urinary system in axials with thin sections and reformatted into coronal and sagittal plane [6].

MATERIALS: All patients diagnosable with renal disease before.

Design of study: Cross sectional study for renal disease patients
Study population: (30) Patients were selected to be the sample unit in this study.

An Inclusion Criterion: Saudi patients only with different age, gender Non Saudi patients only with different age, gender diagnosable with renal disease before.

Area of study: The study was conducted in King Fahd Hospital /Tabuk- KSA in Radiology Department.

Duration of study: The study will be conducted from (first January 2020 to first April 2020).

Equipment: CT SEMIENSE unit with 64 slices that uses $\mathrm{X}$ rays and computational and mathematical processes to generate detailed image data of a scanned subject.

\section{RESULTS}

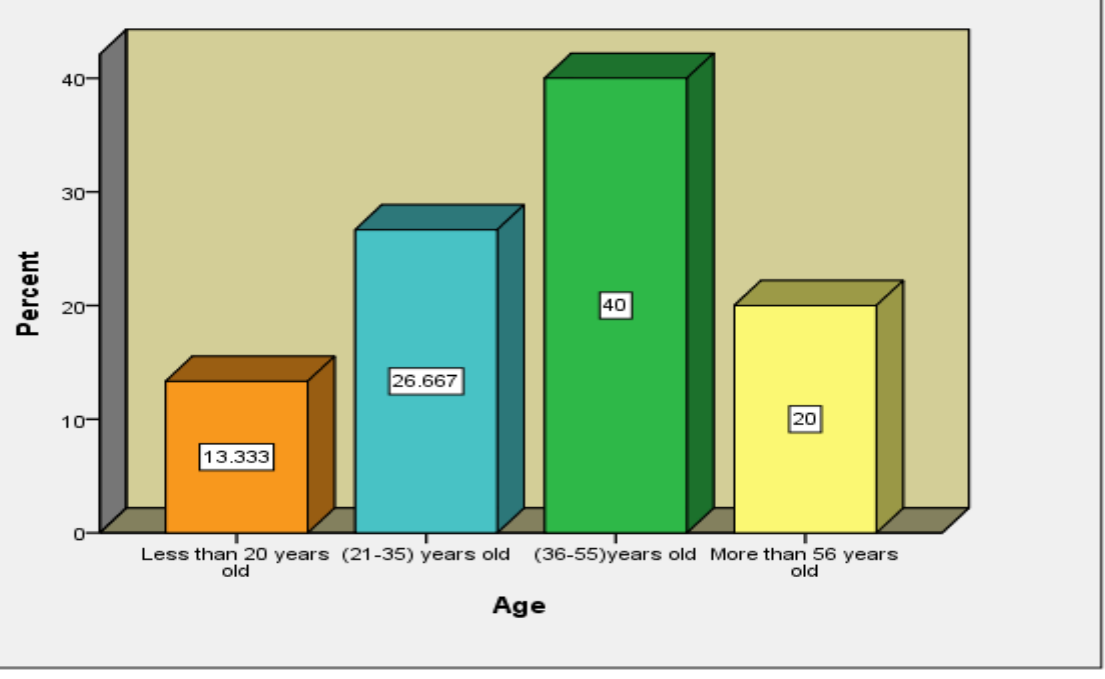

Fig-1: Frequency distribution of age / years

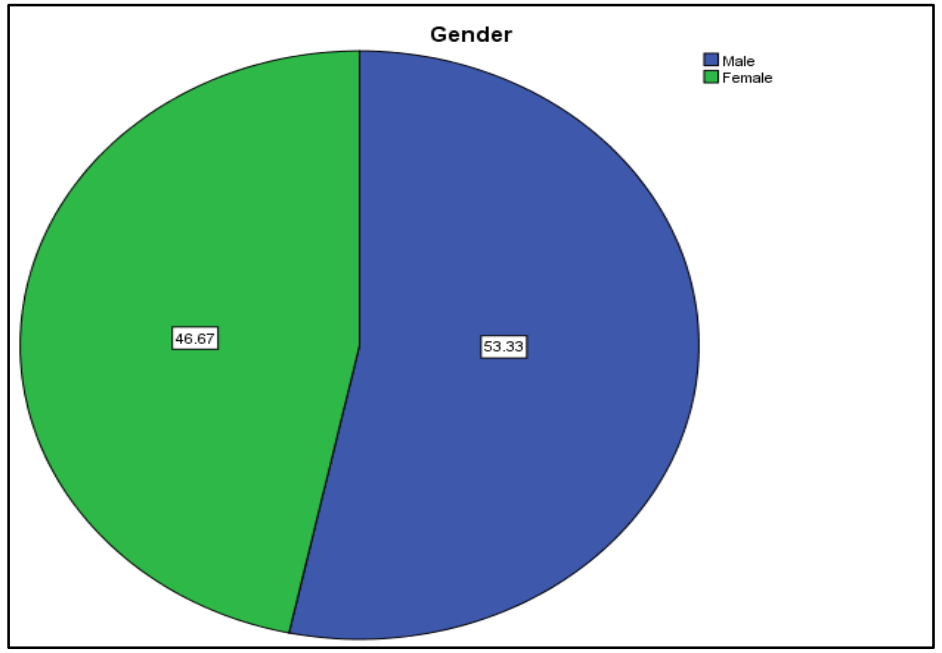

Fig-2: Frequency distribution of gender 


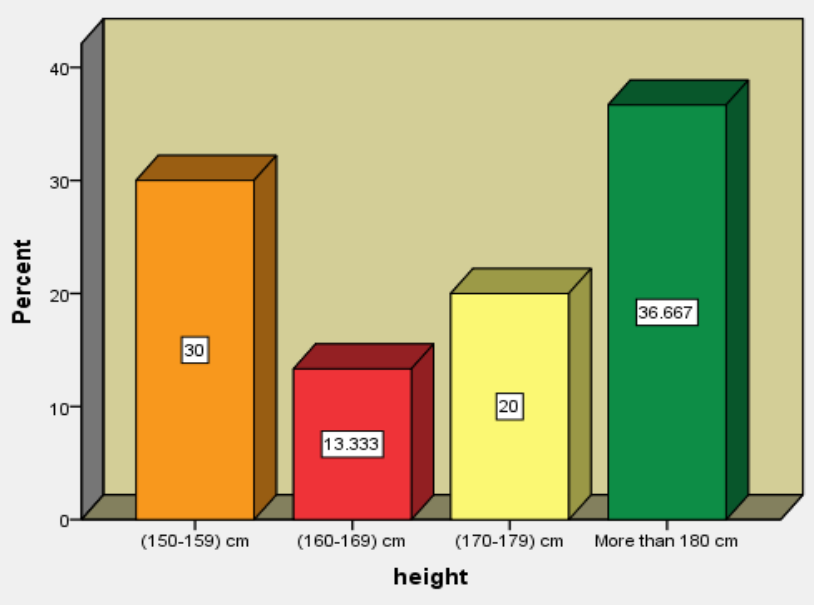

Fig-3: Frequency distribution of patients' height

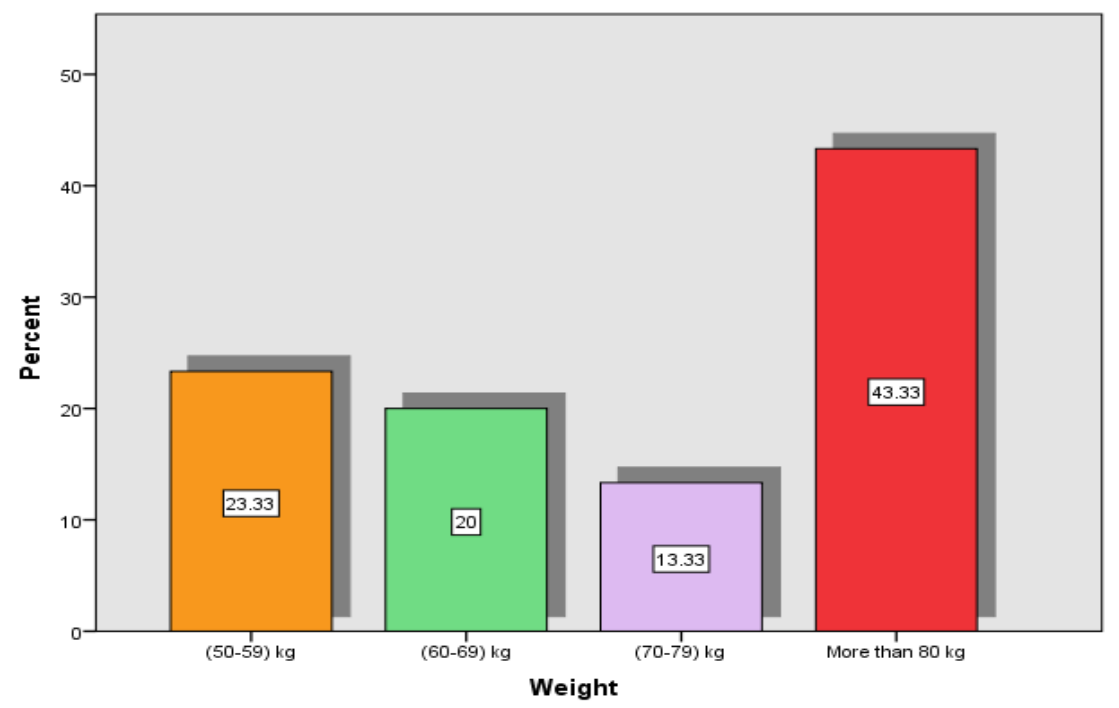

Fig-4: Frequency distribution of weight

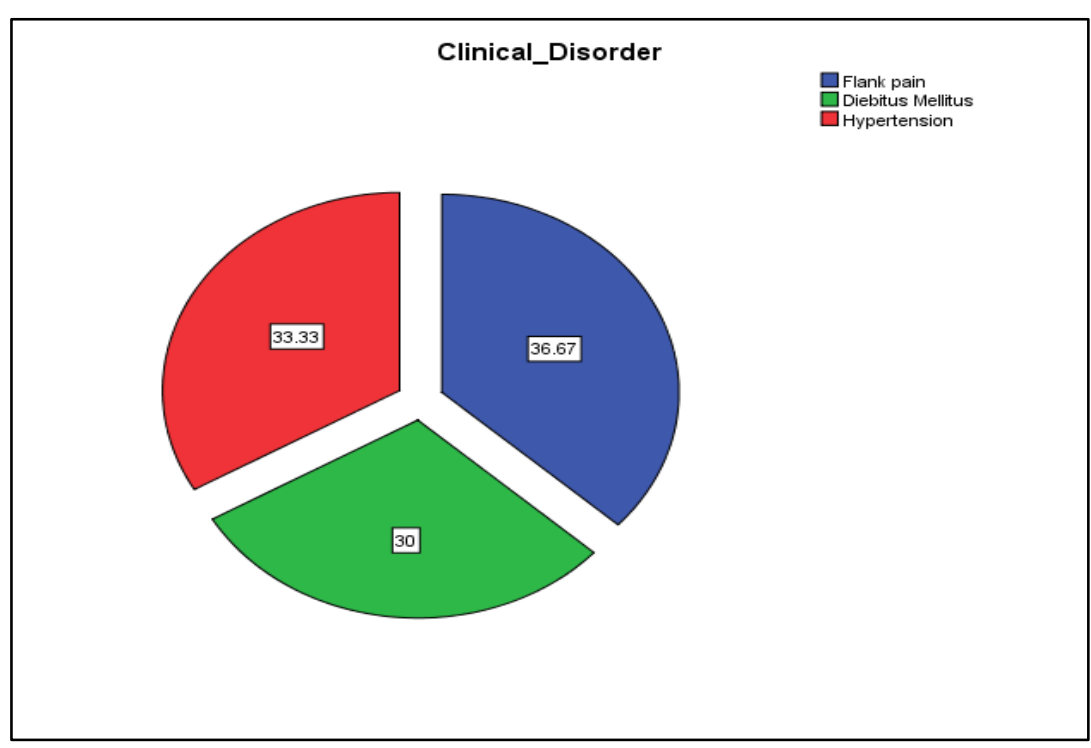

Fig-5: Frequency distribution of clinical diagnosis 


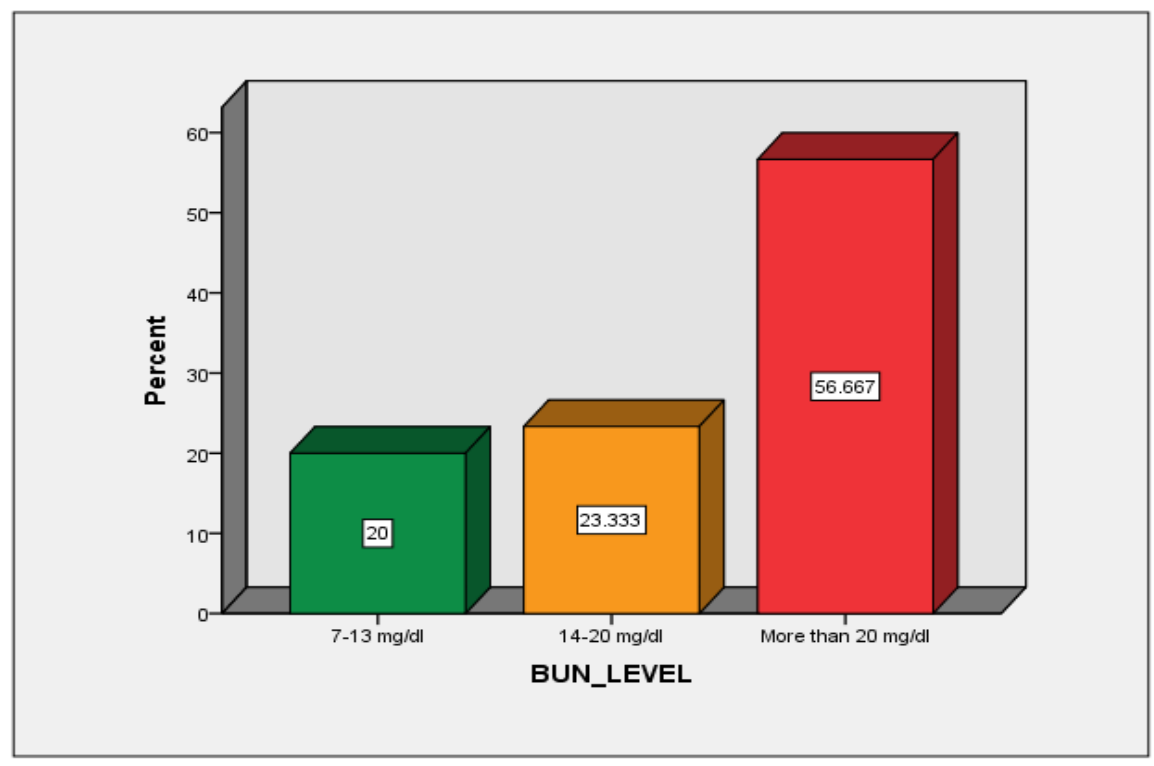

Fig-6: Frequency distribution of lab test Blood Urea Nitrogen level

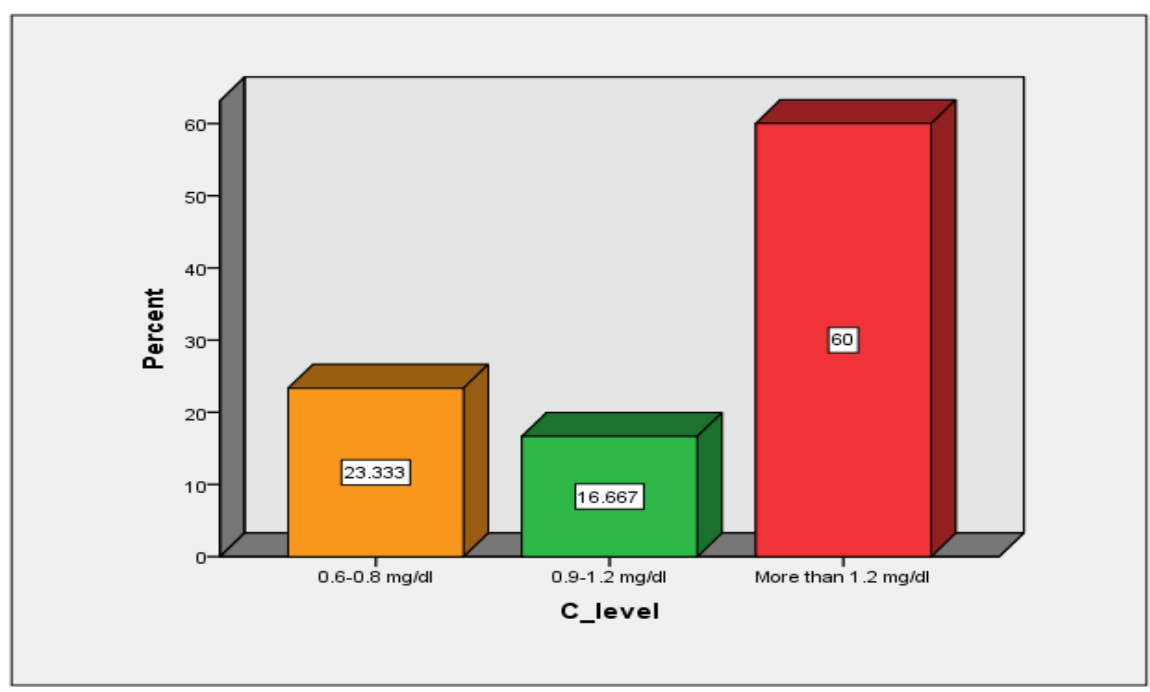

Fig-7: Frequency distribution of creatinine blood test_level

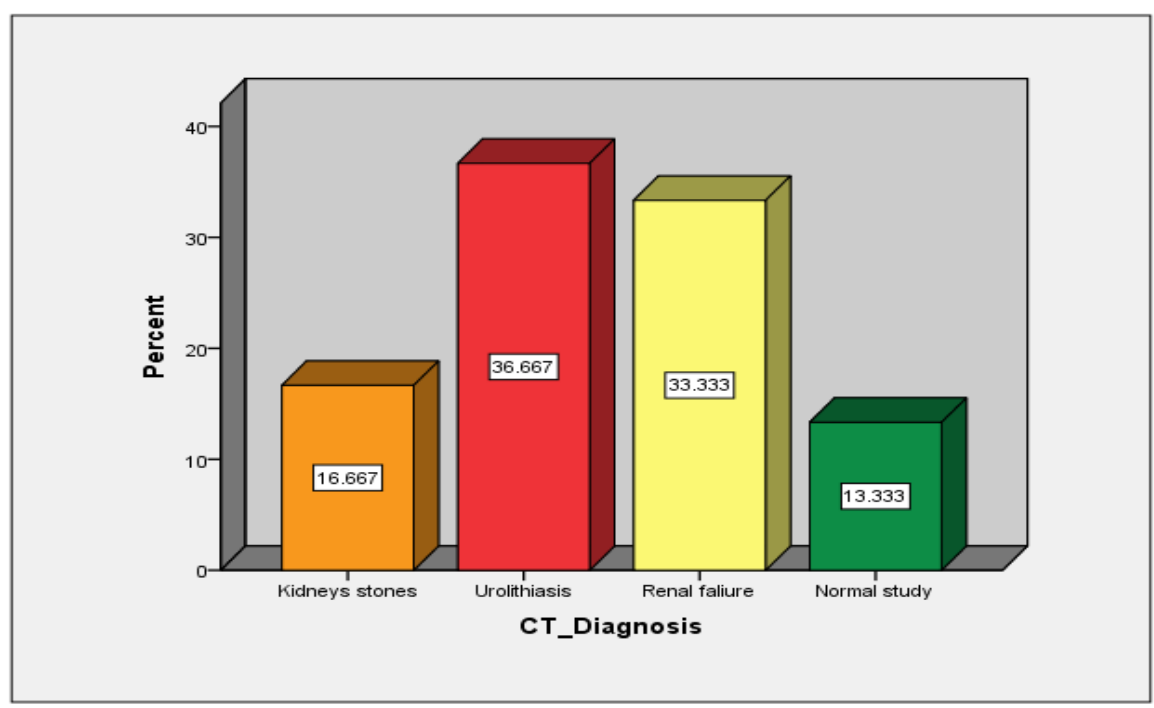

Fig-8: Frequency distribution of CT diagnosis 
Table-1: Correlation between study variables

\begin{tabular}{|c|c|c|c|c|c|c|}
\hline \multicolumn{2}{|l|}{ Correlations } & Age & Height & Weight & BUN_LEVEL & C_level \\
\hline \multirow[t]{3}{*}{ Age } & Pearson Correlation & 1 & .136 & .007 & $-.034-$ & .213 \\
\hline & Sig. (2-tailed) & & .473 & .973 & .859 & .258 \\
\hline & $\mathrm{N}$ & 30 & 30 & 30 & 30 & 30 \\
\hline \multirow[t]{3}{*}{ Height } & Pearson Correlation & .136 & 1 & $.874^{* * *}$ & .223 & $-.049-$ \\
\hline & Sig. (2-tailed) & .473 & & .000 & .236 & .798 \\
\hline & $\mathrm{N}$ & 30 & 30 & 30 & 30 & 30 \\
\hline \multirow[t]{3}{*}{ Weight } & Pearson Correlation & .007 & $.874^{* *}$ & 1 & .239 & $-.017-$ \\
\hline & Sig. (2-tailed) & .973 & .000 & & .204 & .929 \\
\hline & $\mathrm{N}$ & 30 & 30 & 30 & 30 & 30 \\
\hline \multirow[t]{3}{*}{ BUN_LEVEL } & Pearson Correlation & $-.034-$ & .223 & .239 & 1 & $-.002-$ \\
\hline & Sig. (2-tailed) & .859 & .236 & .204 & & .993 \\
\hline & $\mathrm{N}$ & 30 & 30 & 30 & 30 & 30 \\
\hline \multirow[t]{3}{*}{ C_level } & Pearson Correlation & .213 & $-.049-$ & $-.017-$ & $-.002-$ & 1 \\
\hline & Sig. (2-tailed) & .258 & .798 & .929 & .993 & \\
\hline & $\mathrm{N}$ & 30 & 30 & 30 & 30 & 30 \\
\hline
\end{tabular}

\section{DISCUSSION}

(Figure-1) Represented that frequency distribution of age. The average mean (41.533 16.18154), the most category of age was (36-55) years old, frequency (12) with percentage $(40 \%)$, the scorned group of age was (21-35) years old, frequency (8) with percentage $(26.7 \%)$, the other category of age was (more than 56 years old), frequency (6) with percentage $(20 \%)$, (less than 20 years old) frequency (4) with percentage $(13.3 \%)$.

(Figure-2) represented frequency distribution of gender, the male were common (16) with percentage $(53.3 \%)$ and the female (14) with percentage (46.7\%).

(Figure-3) frequency distribution of patients' height showed that the average mean was $(171.37 \pm$ 15.849). The commonest height was more than $180 \mathrm{~cm}$ with frequency (11) and percentage $(36.7 \%)$. The second range was (150-159) $\mathrm{cm}$ with frequency (9) and percentage $(30 \%)$. The other ranges were $(170-179) \mathrm{cm}$ and (160-169) $\mathrm{cm}$ with frequencies (6) and (4) with percentages (20\%) and (13\%) respectively.

(Figure-4) frequency distribution of patients' weight showed that the average mean was $(171.5669 \pm$ 14.96820). The commonest weight was more than $80 \mathrm{~kg}$ with frequency (13) and percentage (43.3\%). The second range was (50-59) $\mathrm{kg}$ with frequency (7) and percentage $(23.3 \%)$. The other ranges were $(60-69) \mathrm{kg}$ and (70-79) $\mathrm{kg}$ with frequencies (6) and (4) with percentages $(20 \%)$ and $(13.3 \%)$ respectively.

(Figure-5) represented that frequency distribution of clinical disorders. The most disorders was patients with flank pain (11) with percentage (36.7 $\%)$ The second category was a hypertensive patient (10) with percentage $(33.3 \%)$. Last clinical disorder was Diabetes Mellitus patients (9) with percentage (30\%).
(Figure-6) showed that the frequency distribution of lab test BUN level. The most patients (17) had high level of blood urea nitrogen (BUG) more than $20 \mathrm{ml} / \mathrm{dl}$ with percentage $(56.7 \%)$. The second category with range of BUN (14-20) mgdl (7) patients with percentages $(23.3 \%)$. The last group of normal BUN (6) with percentage (20\%)

(Figure-7) represented that the frequency distribution of lab test C- level. The most patients (18) had high $\mathrm{C}_{-}$level more than $1.2 \mathrm{ml} / \mathrm{dl}$ with percentage $(60 \%)$. The second category (7) in ranges of (0.6-0.8) mgdl with percentages $(23.3 \%)$. The last category (5) patients with ranges (0.9-1.2) mgdl with percentage $(16.7 \%)$.

(Figure-8) represented that the frequency distribution of CT diagnosis. urolithiasis was the commonest pathology that diagnosis by $\mathrm{CT}$ procedures (11) cases with percentage (36.7\%). Also renal failure came in the second category of CT finding (10) with percentage $(33.3 \%)$. Kidneys stones were found in (5) with percentage $(16.7 \%)$. Only (4) patients were normal study with percentage (13.3\%)

(Table-1) represented a correlation by one simple T-test between the study variables (age, weight, height and laboratory investigation for renal pathology patients whom came to confirm laboratory and clinical disorders by $\mathrm{CT}$ scan. There was a significant correlation between patient age, weight at $\mathrm{P}$ value $(0.007)$ and between age and BUN at $\mathrm{P}$ value $(0.03)$. Also there was a significant correlation between weight and height at $\mathrm{P}$ value $(0.00)$. For laboratory investigation there was a strong significant correlation between (BUN level) and (Creatinine level) at $\mathrm{P}$ value (0.002). 


\section{Conclusion}

The study shows that a CT is an effective modality that can confirm patients' clinical disorders and laboratory investigation for renal system pathology.

- The most age that affected with renal pathology were (36-55) years old.

- The most affected gender with renal pathology was male (16) more than female.
- The commonest renal pathology among Saudi population was ureters stones

- There was a significant correlation between patient age, weight at $\mathrm{P}$ value $(0.007)$ and between age and BUN at $P$ value (0.03).

- Also there was a significant correlation between weight and height at $P$ value (0.00).

- For laboratory investigation there was a strong significant correlation between (BUN level) and (Creatinine level) at $\mathrm{P}$ value (0.002).

\section{APPENDICES}

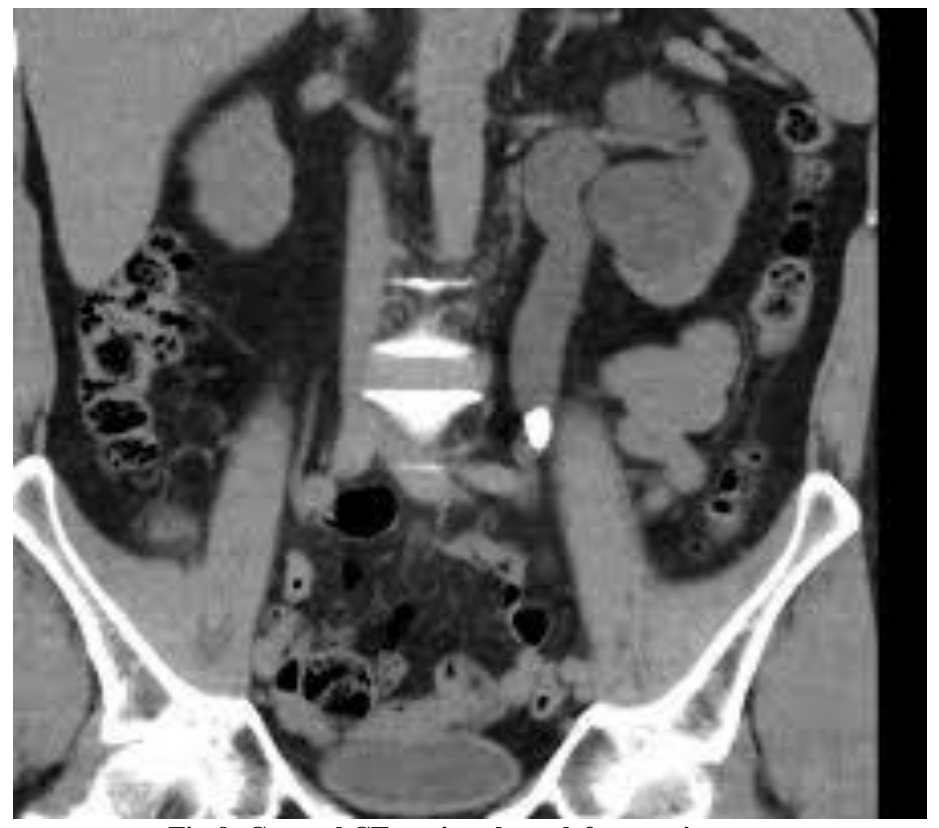

Fig-9: Coronal CT section shows left ureteric stone

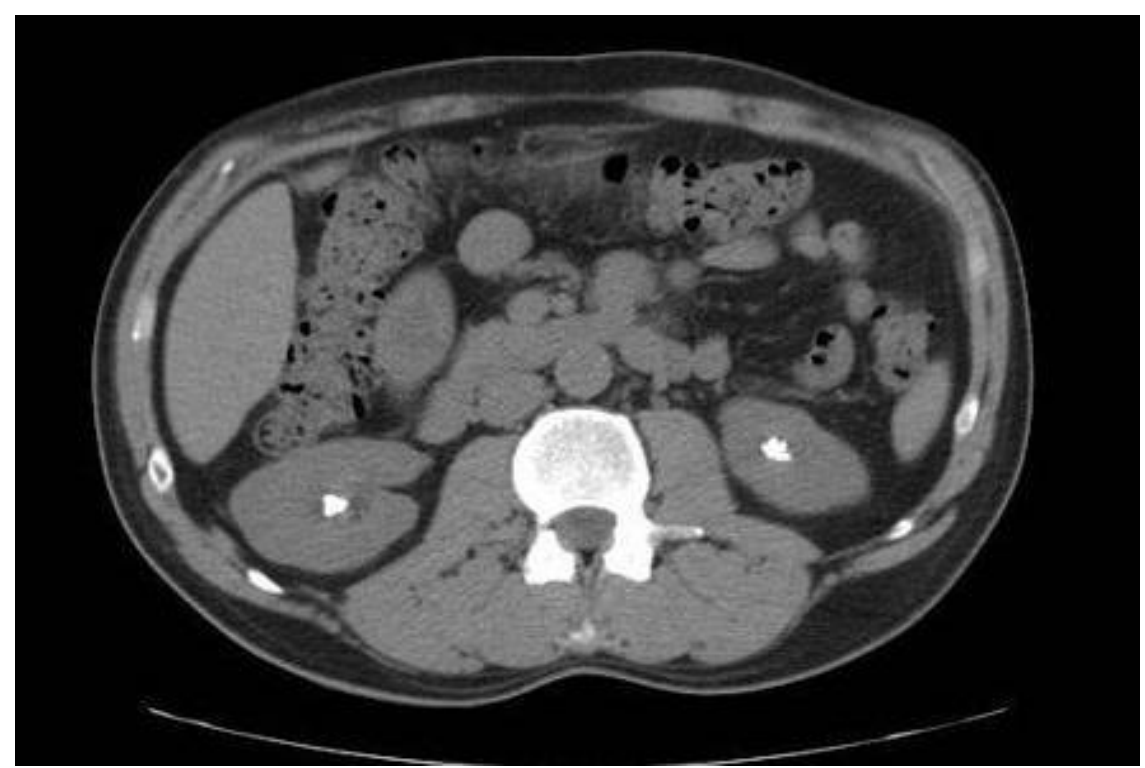

Fig-10: CT image show the kidneys stones 


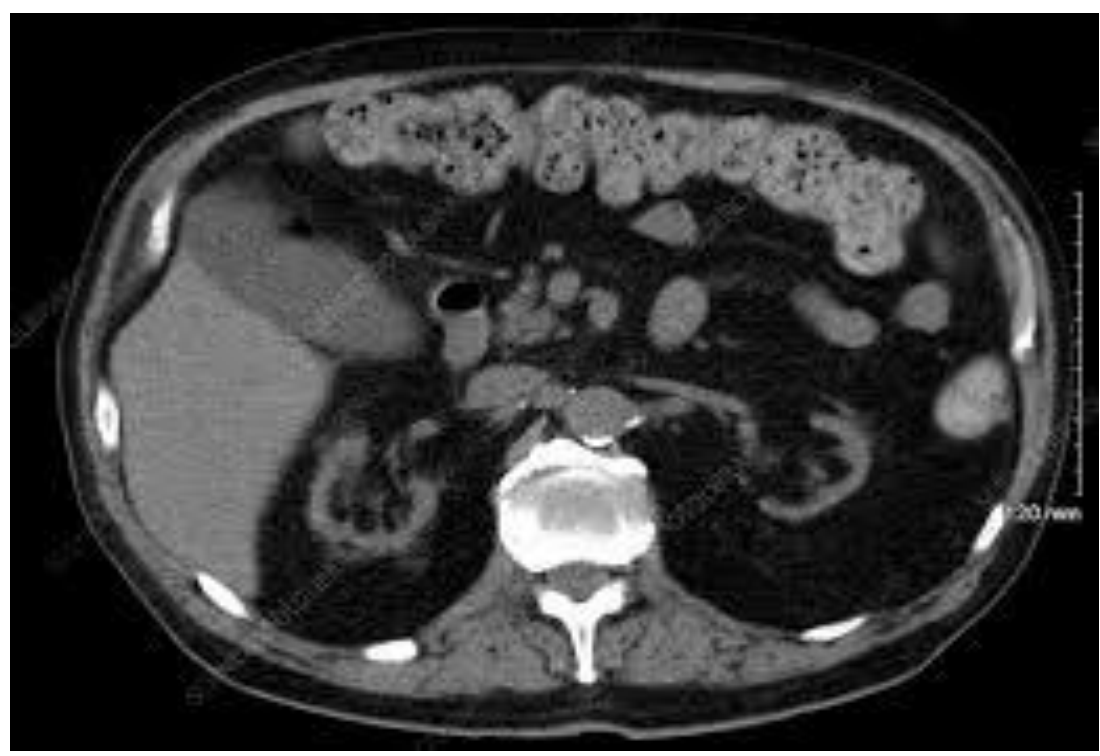

Fig-11: Axial CT image show the chronic renal failure

\section{REFERENCES}

1. Paul L, Talhar SS, Waghmare JE, Kale S, Shende MR. Relationship of Renal Length with Height and Weight of an Individual using Computed Tomography. Journal of Clinical \& Diagnostic Research. 2018 May 1;12(5): 1700-1708.

2. Sumana G, Babu GA. Prediction of Nephrolithiasis Based on Extracted Features of CT-Scan Images using Artificial Neural Networks. International Journal of Advanced Research in Computer Science. 2017 May 15;8(5).

3. Adibi A, Mortazavi M, Shayganfar A, Kamal S, Azad R, Aalinezhad M. Relationship between renal volume calculated by using multislice computed tomography and glomerular filtration rate calculated by using the Cockcroft-Gault and modification of diet in renal disease equations in living kidney donors. Saudi Journal of Kidney Diseases and Transplantation. 2016 Jul 1;27(4):671.

4. Alkhateeb SS, Alothman AS, Addar AM, Alqahtani RA, Mansi TM, Masuadi EM. Kidney cancer in Saudi Arabia: A 25-year analysis of epidemiology and risk factors in a tertiary center. Saudi medical journal. 2018 May;39(5):459.

5. Nassir AM. Prevalence and characterization of urolithiasis in the Western region of Saudi Arabia. Urol Ann. 2019; 11:347-52.

6. Romans L. Computed Tomography for Technologists: A comprehensive text. Lippincott Williams \& Wilkins; 2018 Aug 7. 